\title{
Alteration of Macrophage Infiltrating Compartment: A Novel View on Oral Carcinogenesis
}

\author{
Manabu Shigeoka ${ }^{\mathrm{a}}$ Yu-ichiro Koma ${ }^{\mathrm{a}}$ Mari Nishio $^{\mathrm{a}}$ Masaya Akashi ${ }^{\mathrm{b}}$ \\ Hiroshi Yokozaki ${ }^{a}$ \\ aDivision of Pathology, Department of Pathology, Kobe University Graduate School of Medicine, Kobe, Japan; \\ ${ }^{b}$ Division of Oral and Maxillofacial Surgery, Department of Surgery Related, Kobe University Graduate School of \\ Medicine, Kobe, Japan
}

\section{Keywords}

Oral carcinogenesis $\cdot$ Macrophage $\cdot$ Infiltrating

compartment

\begin{abstract}
Background: The mortality of oral squamous cell carcinoma (OSCC) has remained high for decades; therefore, methods for early detection of OSCC are warranted. However, in the oral cavity, various mucosal diseases may be encountered, including reactive lesions and oral potentially malignant disorders, and it is difficult to differentiate OSCC from these lesions based on both clinical and histopathological findings. It is well known that chronic inflammation contributes to oral cancer development. Macrophages are among the most common inflammatory cells in cancer stromal tissue and have various roles in cancer aggressiveness. Although the roles of macrophages in cancer development have attracted attention, only a few studies have linked macrophages to carcinogenesis, particularly, oral precancerous lesions. Summary: This review article consists of 3 parts: first, we summarize current knowledge on macrophages in human various epithelial precancerous lesions, excluding the oral cavity, to show the importance and gaps in knowledge regarding macrophages in carcinogenesis; second, we review pub-
\end{abstract}

lished data related to the role of macrophages in oral carcinogenesis; finally, we present a novel view on oral carcinogenesis, focusing on crosstalk between epithelial cells and macrophages. Key Messages: The biological features of macrophages in oral carcinogenesis differ drastically depending on the anatomical compartment that they infiltrate. Focusing on the alteration of macrophage infiltrating compartment may serve as a useful novel approach for studying the role of the macrophages in oral carcinogenesis and for gaining further insight into cancer prevention and early detection.

(c) 2021 S. Karger AG, Basel

\section{Introduction}

Histologically, most malignant tumors in the oral cavity are diagnosed as oral squamous cell carcinoma (OSCC). The mortality rate of OSCC is high, and it has remained largely unchanged for the past several decades [1]. Therefore, steps toward prevention and efficient methods for early detection are desired. Moreover, the precise mechanism of oral early carcinogenesis should be clarified. Oral leukoplakia (OL) is a common precancerous lesion, and it has been reported that $0.13-34.0 \%$ of 
these develop into OSCC [2]. The malignant potential of $\mathrm{OL}$ is associated with the degree of epithelial dysplasia, and this observation has resulted in improved prognosis in patients with OSCC. Therefore, many research groups have investigated oral carcinogenesis, focusing on epithelial dysplasia in OL; however, the underlying mechanism has not been fully elucidated. The main reason for this is that the conventional method for histological evaluation of OL is challenging compared with that of other precancerous lesions. In fact, several researchers proposed that local biopsy of OL is likely to underdiagnose the condition $[3,4]$, and oral epithelial dysplasia is distinct from other types of epithelial dysplasia found in the head and neck region according to the World Health Organization classification [5].

OSCC is a cancer closely associated with chronic inflammation. Risk factors include not only cigarette smoking and alcohol use but also oral specific factors, such as dental trauma and the presence of periodontopathogenic bacteria [6-11]. In addition, chronic inflammatory-like oral diseases, including OL and oral lichen planus, exhibit malignant potential in association with OSCC [12]. Based on this knowledge, independent carcinogenic mechanisms in association with chronic inflammation in the oral epithelium should be considered, when establishing the diagnosis and designing efficacious treatment strategies for patients with oral precancerous lesion.

\section{Macrophages in Cancer Microenvironments}

Chronic inflammation is considered a major pathological feature of tumor development. Inadequate elimination of the inflammatory response leads to various cancer-associated disorders [13]. Moreover, Dvorak [14] proposed that tumors are wounds that do not heal, and accumulating investigations have added support to this hypothesis [15-19]. Therefore, in cancer tissue, infiltration and activation of inflammatory cells are observed in the same manner as in the wound healing process, and it could be considered that the cancer microenvironment, in which such biological responses occur, enhances the malignant phenotype of cancer cells.

Inflammation can either prevent/restrain or shape/ promote tumor development, and tumorigenesis-associated inflammation is referred to as "cancer immunoediting," which proceeds through the 3 phases known as "elimination," "equilibrium," and "escape" [20-22]. However, it has not been entirely elucidated how oral carcinogenesis is interpreted in this context.
It is well known that macrophages infiltrate various types of human cancer tissue, a pathological manifestation associated with a poor prognosis [23-25]. The dual role of macrophages has been explained by their functional plasticity. M1 (classically activated) macrophages produce type I proinflammatory cytokines such as interleukin (IL)-1 $\beta$, IL- $1 \alpha$, IL- 12 , tumor necrosis factor- $\alpha$, and glial fibrillary acidic protein $[26,27]$. Conversely, M2 (alternatively activated) macrophages produce type II cytokines, such as IL-4, IL-6, and IL-10, promoting anti-inflammatory responses $[27,28]$. Phenotypically, inducible nitric oxide synthase, human leukocyte antigen-DR, CD80, CD86, CD169, and TLRs 2 and 4 are induced by M1 macrophages, whereas M2 macrophages upregulate CD163, CD204, CD206, and arginase-1 [29].

From an oncological view point, the concept is widely accepted that M1 macrophages are tumor suppressive, whereas M2 macrophages have tumorigenic functions [30-33]. M1 macrophages facilitate tumor-specific antigen presentation [34]. Moreover, M1 macrophages reportedly kill cancer cells by tumor-killing molecules (such as reactive oxygen species or nitric oxide) or antibodydependent cellular cytotoxicity [35]. Conversely, M2 macrophages are widely known to promote tumorigenesis, angiogenesis, matrix remodeling, and metastasis [36]. Cancer metastasis is a critical cause for the lower survival rate of patients with malignancies. It has been revealed that several macrophage-derived humoral factors contribute to the migration of cancer cells [37-42]. In addition, the relationship between macrophages and epithelial-to-mesenchymal transition, which is a basic process in metastasis, has also been shown [43-45].

A therapeutic strategy that can target macrophage polarization has been proposed. Corosolic acid and oleanolic acid inhibited the proliferation of glioblastoma cells by suppression of M2 skewing of macrophages [46, 47]. The repolarization of the M2 macrophage to an M1 phenotype normalized the structure of the tumor blood vessels, whereas M2 macrophages were involved in the formation of abnormal dysfunctional blood vessels [48-52]. As described above, the M1/M2 balance of macrophage polarization has been considered an important concept in the tumor microenvironment.

\section{Tumor-Associated Macrophages in OSCC}

Macrophages infiltrating cancer tissue are named tumor-associated macrophages (TAMs), and a considerable proportion of these are skewed toward the M2 phe- 
Table 1. The oncogenic roles of macrophages in human epithelial tumors excluding those of the oral cavity

\begin{tabular}{|c|c|c|}
\hline Tumor type & $\begin{array}{l}\text { Human-macrophage } \\
\text { marker }\end{array}$ & Roles of macrophages (references) \\
\hline \multirow[t]{2}{*}{ Laryngeal carcinogenesis } & CD68 & Progression from premalignant lesions to malignancy [63] \\
\hline & CD163 & $\begin{array}{l}\text { Positive correlation between the number of intraepithelial } \mathrm{CD} 163^{+} \text {macrophages } \\
\text { and the histological grade of dysplasia [64] }\end{array}$ \\
\hline Gastric carcinogenesis & CD204 & Proliferative activity in gastric adenoma [65] \\
\hline Colorectal carcinogenesis & CD68 and CD163 & $\begin{array}{l}\text { Morphology and size of polyploid and nonpolyploid precancerous lesions in } \\
\text { colorectal adenoma [67] }\end{array}$ \\
\hline $\begin{array}{l}\text { Hepatocellular } \\
\text { carcinogenesis }\end{array}$ & - & Alcohol-related liver disease [68] \\
\hline \multirow{2}{*}{$\begin{array}{l}\text { Uterine cervical } \\
\text { carcinogenesis }\end{array}$} & CD68 and CD163 & $\begin{array}{l}\text { The association between both } \mathrm{CD}^{+} 8^{+} \text {and } \mathrm{CD} 63^{+} \text {macrophages and high-risk } \\
\text { HPV infection [71] }\end{array}$ \\
\hline & CD163 & HPV infected cervical lesion severity [72] \\
\hline Endometrial carcinogenesis & CD68 & PR loss and progression of precancerous endometrial lesions [73] \\
\hline $\begin{array}{l}\text { Ovarian epithelial } \\
\text { carcinogenesis }\end{array}$ & $\begin{array}{l}\text { CD68, CD163, and } \\
\text { CD204 }\end{array}$ & $\begin{array}{l}\text { Higher number of macrophages in borderline and malignant tumors than in } \\
\text { benign tumors [74] }\end{array}$ \\
\hline Prostate carcinogenesis & CD68 and CD204 & The high $\mathrm{CD} 24^{+}$versus $\mathrm{CD} 68^{+}$ratio increased in PIN and adenocarcinoma [75] \\
\hline Breast carcinogenesis & CD68 & Higher levels of $\mathrm{CD}^{+} 8^{+}$macrophages in high-grade DCIS [76] \\
\hline
\end{tabular}

CD, cluster of differentiation; IL, interleukin; PD-L1, programmed death-ligand 1; BilIN, biliary intraepithelial neoplasia; IPNB, intraductal papillary neoplasm of the bile duct; HPV, human papillomavirus; PR, progesterone receptor; PIN, prostatic intraepithelial neoplasia; DCIS, ductal carcinoma in situ.

notype $[53,54]$. Many studies of OSCC reported the significance of TAMs. Levels of CD11b-positive myeloid cells and CD206-positive TAMs are increased in human OSCC specimens during postradiotherapy recurrence [55]. On the other hand, most of human OSCC studies have used CD163 as an M2 macrophage marker. TAMs expressing CD163 significantly correlated with a poor prognosis in OSCC patients [56-60]. Currently, CD163 might be considered a more suitable M2 marker in OSCC patients. However, Xiao et al. [61] demonstrated that migration of OSCC cells was promoted by M1-like macrophages activated by exosome-transferred THBS1. Moreover, TAMs in oral premalignant lesions coexpress CD163 and STAT1, suggesting that the TAMs involved in oral precancerous lesions exhibit the M1 phenotype in a Th1-dominated microenvironment [62]. These studies introduced the hypothesis that macrophages might exhibit not only the M2 but also the M1 phenotype in oral carcinogenesis.

\section{Learning from the Biological Features of Macrophages in Nonoral Carcinogenesis}

A summary of the roles of macrophages in nonoral carcinogenesis is provided in Table 1. The listed reports are based on investigations using human clinical samples. Macrophages are associated with several types of epithelial carcinogenesis in various organs, such as the larynx, stomach, colorectum, liver, bile duct, uterine cervix, en- 
dometrium, ovary, prostate, and breast (Table 1). The immunohistochemical investigations leading to these observations used CD68 [63, 67, 70, 71, 73-76], CD163 [64, 67, $69,71,72,74,77]$ or CD204 $[65,66,74,75]$ as macrophage markers in human clinical samples. Interestingly, several studies of human squamous cell carcinogenesis identified CD163 as a suitable marker. However, the investigations of other types of carcinogenesis also used CD163. It has been speculated that the association between macrophage markers and carcinogenic stage might differ depending on the histological type involved.

Interestingly, only one study showed the significance of intraepithelial macrophages in laryngeal epithelial dysplasia using human clinical samples [64]. Although the significance of the interaction between epithelial cells and macrophages has been well established by in vitro or in vivo experiments, further studies of epithelial cell-macrophage interaction focusing on macrophage distribution are required.

Recently, the contribution of macrophages to alcohol-related liver carcinogenesis was studied [68]. Several investigators demonstrated a relationship between macrophages and human papillomavirus infection [71, 72]. Because human papillomavirus infection is widely known to be major risk factors of OSCC [5], it is speculated that the carcinogenic mechanism proposed in these studies of cervical cancer could be applied to the progression of oral precancerous lesions. The macrophage skewing depends on each risk factor, and it is the combination of these that constitutes the carcinogenic microenvironment.

\section{Suitable Macrophage Markers in Oral Carcinogenesis}

Most studies of macrophages in oral carcinogenesis have been performed focusing on CD163 expression [62, $78,81-84,91]$. We previously confirmed that the number of infiltrating $\mathrm{CD} 163^{+}$macrophages but not the numbers of $\mathrm{CD}_{206^{+}}$and $\mathrm{CD} 204^{+}$macrophages significantly correlated with various clinicopathological factors in patients with tongue leukoplakia (TL) [78]. Another study relying on immunohistochemical analyses demonstrated $\mathrm{CD}^{+} 8^{+}$and $\mathrm{CD} 163^{+}$macrophage infiltration in carcinoma in situ (CIS), while the number of CD204 $4^{+}$cells was substantially lower [79]. Meanwhile, $\mathrm{CD} 204^{+}$macrophages significantly correlated with the recurrence and cancerization of patients with oral epithelial precancerous lesions [80]. The reason for this discrepancy is unknown. Since oral precancerous lesions include multiple diseases in addition to OL [5], the expression of these markers may differ depending on the pathogenesis of each disease.

\section{Macrophage Polarization in Oral Carcinogenesis}

Regarding macrophage polarization in oral carcinogenesis, M1/M2 dichotomy should be carefully considered. The first reason is that no ideal immunohistochemical markers exist to detect M1 macrophages [29]. Additionally, in a monoculture assay, it was reported that monocytes weakly express CD163 [79]. Mori et al. [62] demonstrated that $\mathrm{CD} 163^{+}$macrophages in OL express STAT1, which is known as an M1-related marker. In OL with malignant transformation tissue, the number of macrophages expressing CD11c, one of the M1 markers, was significantly higher than in OL with nontransformation [81]. Another study of OL focused on signal regulatory protein a (SIRPa), which primes phagocytosis of cancer cells. This study showed that the percentages of $\mathrm{CD} 63^{+}$or $\mathrm{CD} 8^{+}$macrophages coexpressed with SIRPa were higher in OL as compared with OSCC, and a coculture system of macrophage-like cells and oral cancer cells revealed transitory upregulation of SIRPa expression [82]. It was speculated that macrophages are educated by M1-inducible stimulation and are switched to the M2 phenotype due to acquired resistancebyanymechanism(s) in oral carcinogenesis. It would be reasonable to hypothesize that macrophages show overlapping phenotypes of M1 and M2 during oral carcinogenesis.

Interestingly, a study using human OSCC samples revealed that in contrast to macrophages expressing CD163, inducible nitric oxide synthase-positive macrophages were distributed in the tumor periphery, the peritumoral noncancerous area, and in the subepithelial stroma of OL. This study suggested that macrophages are educated by tumor cells to polarize from M1 to M2 along with carcinogenic progression [83]. It could be expected that the biological features of macrophages located in the stroma are not identical to those of the intratumoral macrophages.

Moreover, we previously evaluated the role of macrophages in benign lesions that are difficult to distinguish from oral cancer. In oral candidiasis, oral lichen planus, and aphthous stomatitis, $\mathrm{CD} 163^{+}$macrophages were present in the subepithelial area but not in the epithelial area [84]. In oral verruciform xanthoma, which is a rare reactive lesion characterized by accumulation of foamy macrophages in the stroma, it was suggested that foamy 
cells express the $\mathrm{M} 2$ marker $\mathrm{CD} 163^{+}$and may be involved in morphogenesis by vascular endothelial growth factor expression-mediated angiogenesis [85]. These findings stress that it is difficult to establish a discrimination system of M1 and M2 macrophage phenotypes in oral mucosal lesions based only on macrophage markers.

\section{The Distribution of Macrophages in Oral Carcinogenesis}

Forty-five years ago, researchers observed macrophages in oral dysplastic epithelium. The macrophages phagocytosed dysplastic epithelial cells [86, 87]. In 1995, it was showed that macrophages were rarely present in healthy oral epithelium [88]. It was also reported that the number of macrophages increased in the subepithelial tissue of OL with dysplasia [88]. In 2015, an immunohistochemical study was performed based on macrophage polarization and revealed that CD163-expressing macrophages are deployed to the stromal area in OL [62]. The important point to note is that many researchers have proposed that most macrophages in OL infiltrate into the subepithelial stroma [62, 78, 82, 83, 88-91]. Reportedly, in early stages of squamous cell carcinoma of the lower lip, neoplastic epithelial cells recruited macrophages into their microenvironment to escape antitumor immune responses [92]. We previously demonstrated the correlation of subepithelial $\mathrm{CD}_{163^{+}}$macrophage infiltration with immunosuppressive cytokine IL-10 expression in TL [78]. A "distant" crosstalk separated by the basement membrane between epithelial cells and stromal macrophages may be formed in the early stage of oral carcinogenesis.

Meanwhile, some studies observed intraepithelial macrophages in CIS $[79,93]$. Our retrospective immunohistochemical analysis using TL biopsy specimens and consecutive resected specimens revealed that the TL with invasive cancer had significantly higher numbers of intraepithelial $\mathrm{CD}_{163}{ }^{+}$macrophages than the TL with noninvasive cancer [84]. We recently observed intraepithelial $\mathrm{CD} 63^{+}$macrophages in a case of oral lichenoid disease with malignant potency [94]. Interestingly, Weber et al. [81] demonstrated that malignant transformation of $\mathrm{OL}$ is significantly associated with macrophage infiltration toward the epithelium using not only CD163 but also CD11c, which is an M1-related marker. Their findings support the theory that the M1 macrophage phenotype overlaps with the M2 phenotype in oral carcinogenesis. They also suggest that macrophages exhibit different biological features depending on the compartment that they infiltrate and that direct contact of macrophages with epithelial cells is important in the malignant transformation of OL. In fact, macrophages/oral cancer cell adhesion via ICAM-1 was reported based on both in vitro assays and immunohistochemical examination [95]. Additionally, macrophages cocultured directly with oral cancer cells induced CD204 expression [79].

These findings indicate that the dramatic change in macrophage localization could help identifying OL patients with malignant potential, and it has been speculated that the adhesion of these cells contributes to oral carcinogenesis. Meanwhile, microscopic observations revealed that the number of epithelial cells is substantially higher than macrophages. Therefore, it is reasonable to consider that not only these adhesive mechanisms but also interaction through humoral factor(s) should be taken into consideration. This "close" crosstalk between epithelial cells and macrophages may be an important promoter of oral carcinogenesis.

\section{The Association of Macrophages with Risk Factors of Oral Cancer}

Considering oral cancer as a wound that does not heal, it would appear relevant to hypothesize that the "close" crosstalk between epithelial cells and macrophages, which is induced by smoldering inflammation, contributes to oral carcinogenesis. There are some reports on the relationship between macrophages and specific smoldering inflammation in the oral cavity. Incisional biopsy-induced tissue trauma skewed macrophage polarization toward the M2 phenotype and promoted tumor progression [96]. This mechanism may also be triggered by inadequately fitting dentures, rough teeth surfaces, or inadequate tooth brushing. In addition, it was reported that intraepithelial entrapped blood vessels in CIS are broken down by mechanical stress from growing neoplastic cells [97]. This study hypothesized that macrophage expression of CD163 may be induced to scavenge the collapsed vessels.

With respect to links between macrophages and other risk factors, matrix metalloproteinase 12 expressed in most macrophages plays a significant role in remodeling events occurring in connective tissue during exposure to sunlight in actinic cheilitis [98]. In addition, it was shown that the expression of CD204-postive macrophages in female OSCC patients was higher than that in male patients [80]. Therefore, sex-related hormonal abnormalities or autoimmune diseases may be involved in macrophage infiltration in oral carcinogenesis. 
Table 2. The role of macrophages in oral carcinogenesis

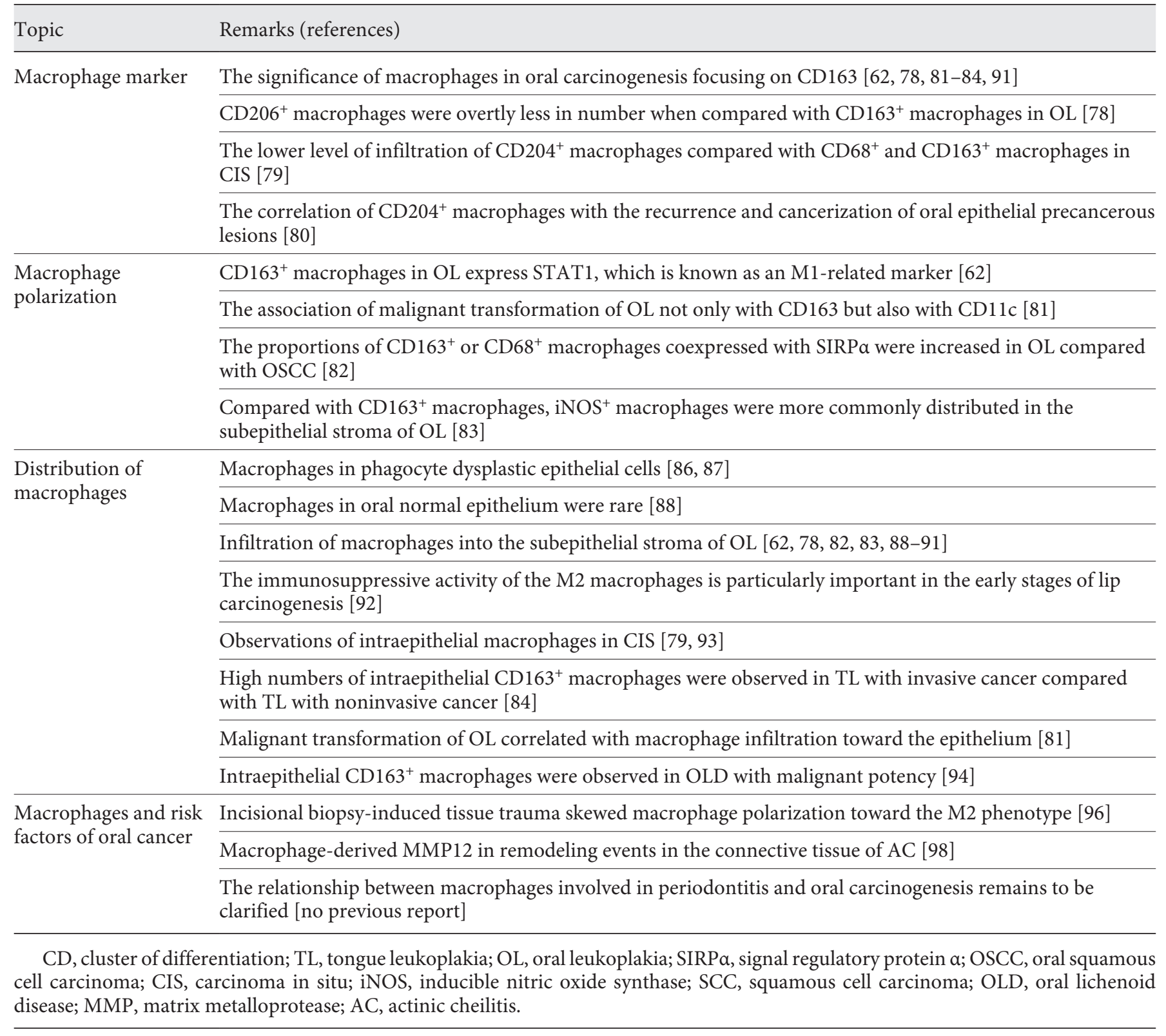

Although periodontal bacterial infection is widely accepted as an independent risk factor in several cancers, including OSCC [99], to the best of our knowledge, the relationship between macrophages in periodontitis and oral carcinogenesis has not been fully clarified. The main reason may be that it is difficult to tease out the M1/M2 dichotomy in periodontitis. In a mouse model, both M1 and M2 macrophage phenotypes were observed in normal gingival tissue, and it was speculated that this mixture of phenotypes might be necessary for tissue homeostasis and immune defense against the commensal oral flora [100]. Furthermore, it was also reported that the prickle cell layer of the masticatory mucosa, including the dorsum of the tongue, gingiva, and palate, expresses PD-L1 under physiological conditions [101]. These reports suggest the peculiarity of the oral mucosa with potentially complex mechanisms in place to prevent excessive inflammation. Further investigation of the role of macrophages in periodontitis-related oral carcinogenesis using human samples is required. 


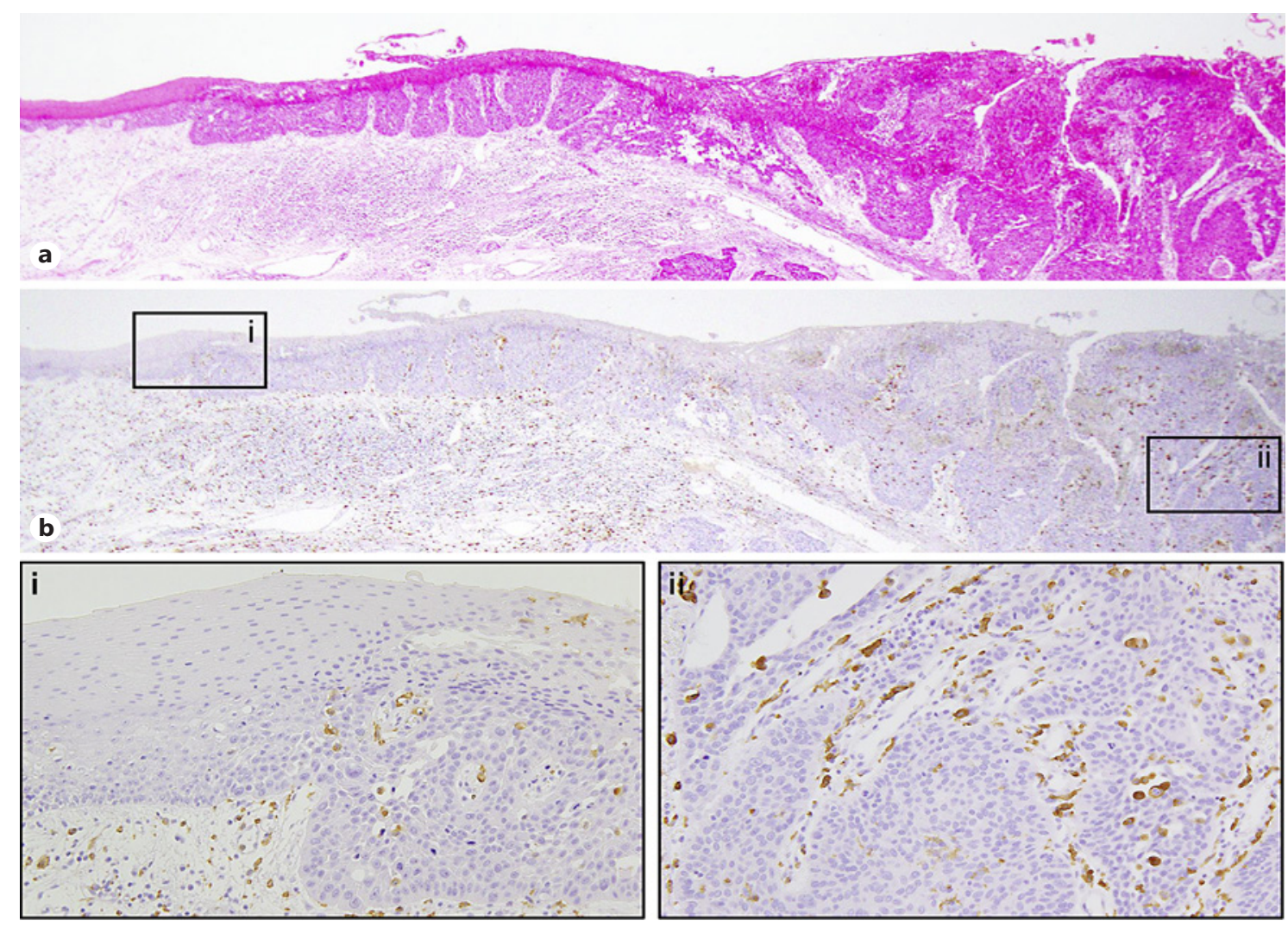

Fig. 1. Immunohistochemical study of CD163 in oral carcinogenesis. a A low-power view of tongue tissue with normal-to-mildly dysplastic epithelium (left side), CIS (middle part), and squamous cell carcinoma (right side) of the resected specimen. Original magnification, $\times 20 . \mathbf{b} \mathrm{CD} 163^{+}$cells are observed in subepithelial area in the normal-to-mildly dysplastic epithelium. Original magnifi- cation, $\times 20$. i A high-power-view CIS accompanied by intraepithelial infiltration of relatively few $\mathrm{CD}_{163}{ }^{+}$cells. Original magnification, $\times 200$. ii In the invasive cancer, the number of $\mathrm{CD} 163^{+}$cells is substantially higher than that observed in the CIS (i). Original magnification, $\times 200$. CIS, carcinoma in situ.

\section{Discussion and Future Perspective}

Many studies have shown the contribution of macrophages to oral carcinogenesis (Table 2). Most of these findings focused on CD163 as a macrophage marker. A strict distinction between M1- and M2-type macrophages may be of limited relevance in studies of oral carcinogenesis. It is speculated that this situation may be specific to the oral epithelium, which is continuously exposed to various inflammatory risk factors. Therefore, alternative views on the role of macrophage feature and methods to differentiate these in oral carcinogenesis are warranted.

Figure 1 provides morphological and CD163 immunohistochemical images of the multistage oral carcinogenesis involved in a surgically resected specimen. In Figure 2, we propose our working hypothesis on the interaction between macrophages and epithelial cells in oral carcinogenesis. When "smoldering inflammation" occurs in the oral mucosa, $\mathrm{CD}_{163^{+}}$macrophages are deployed to the subepithelial stroma, especially to beneath the basement membrane, to prepare for cancer immunoediting. Following this, the "distant" interaction between macrophages and epithelial cells induces the migration of macrophages to the epithelial area through switching of immunoediting from tumor dormancy to uncontrolled tumor outgrowth. More importantly, once the lesion develops into invasive cancer after the appearance of a few intraepithelial macrophages, more $\mathrm{CD}_{163}{ }^{+}$macrophages infiltrate into the cancer nest and in the tissue surrounding the invasive cancer, and the "close" crosstalk between epithelial cells and macrophages is initiated. Macrophages are further polarized to the M2 phenotype (so-called 


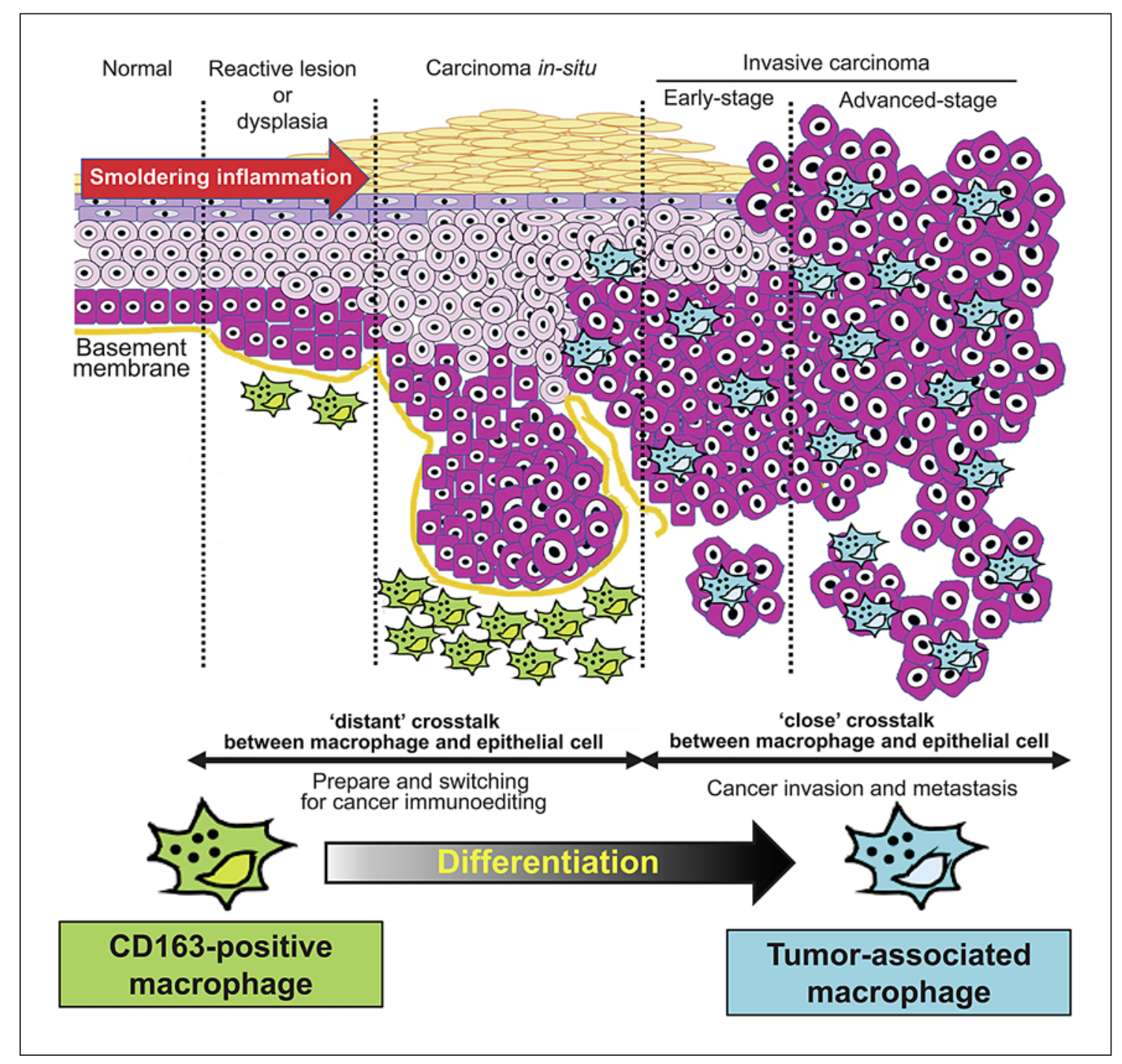

Fig. 2. Schematic representation of the working hypothesis on the interaction between macrophages and epithelial cells in oral carcinogenesis. The "smoldering inflammation" in the oral mucosa promotes the recruitment of $\mathrm{CD} 63^{+}$macrophages to the subepithelial stroma, especially beneath the basement membrane, and prepares for cancer immunoediting. Following this, the "distant" interaction between macrophages and epithelial cells results in a breakdown of the basement membrane through switching of immunoediting from tumor dormancy to uncontrolled tumor outgrowth. Once the basement membrane is destroyed, $\mathrm{CD}_{163^{+}}$mac-

TAMs) and stimulate the invasive and metastatic potential of the epithelial cells. Here, we would like to propose that the clarification of oral carcinogenesis focusing on the alteration of crosstalk between epithelial cells and macrophages from "distant" to "close" may provide noteworthy targets for prevention and early detection of OSCC. rophages infiltrate not only cancer nests but also marginal epithelium, and "close" crosstalk develops between the epithelial cells and the macrophages. Macrophages are further differentiated to TAMs (so-called M2 macrophages) due to this "close" crosstalk, and epithelial cells acquire invasive and metastatic potential. Although the macrophage phenotype is heterogenous and ambiguous, focusing on the compartment subject to infiltration may serve as a useful novel approach for studying the role of the macrophages in oral carcinogenesis and for gaining further insight into cancer prevention and early detection. TAMs, tumor-associated macrophages.

\section{Conclusion}

In conclusion, the biological features of macrophages in oral carcinogenesis differ drastically depending on the anatomical compartment that they infiltrate. Targeting the alteration of macrophage compartment may be pivotal in early detection and effective therapeutics of OSCC. 


\section{Acknowledgements}

The authors are grateful for the assistance provided by all present members of the Division of Pathology, Department of Pathology, Kobe University. We are also grateful to Emeritus Prof. Takahide Komori (Kobe University) and all collaborators who kindly supported the research.

\section{Conflict of Interest Statement}

The authors have no conflicts of interest to declare.

\section{Funding Sources}

This work was supported by Grant-in-Aids for Scientific Research (19K19157) from the Japan Society for the Promotion of Science.

\section{Author Contributions}

M.S. contributed to conceiving the idea, searching the literature, and drafting the manuscript. Y-I.K. and M.N. revised the manuscript. M.A. contributed to reviewing the data. H.Y. supervised the study. All authors reviewed and approved the final version of the manuscript.

\section{References}

1 Petruzzi MN, Cherubini K, Salum FG, de Figueiredo MA. Role of tumour-associated macrophages in oral squamous cells carcinoma progression: an update on current knowledge. Diagn Pathol. 2017;12(1):32.

2 Warnakulasuriya S, Ariyawardana A. Malignant transformation of oral leukoplakia: a systematic review of observational studies. J Oral Pathol Med. 2016;45(3):155-66.

3 Kusukawa J, Suefuji Y, Ryu F, Noguchi R, Iwamoto $\mathrm{O}$, Kameyama T. Dissemination of cancer cells into circulation occurs by incisional biopsy of oral squamous cell carcinoma. J Oral Pathol Med. 2000;29(7):303-7.

4 Holmstrup P, Vedtofte P, Reibel J, Stoltze K. Oral premalignant lesions: is a biopsy reliable? J Oral Pathol Med. 2007;36(5):262-6.

5 Naggar AK, Chan JKC, Grandis JR, Takata T, Slootweg PJ. WHO classification of head and neck tumors. 4th ed. Lyon, France: IARC; 2017. p. 112.

6 Muwonge R, Ramadas K, Sankila R, Thara S, Thomas G, Vinoda J, et al. Role of tobacco smoking, chewing and alcohol drinking in the risk of oral cancer in Trivandrum, India: a nested case-control design using incident cancer cases. Oral Oncol. 2008;44:446-54.

7 Lopes CF, de Angelis BB, Prudente HM, de Souza BV, Cardoso SV, de Azambuja Ribeiro RI. Concomitant consumption of marijuana, alcohol and tobacco in oral squamous cell carcinoma development and progression: recent advances and challenges. Arch Oral Biol. 2012;57(8):1026-33.

8 Lissowska J, Pilarska A, Pilarski P, Samolczyk-Wanyura D, Piekarczyk J, BardinMikolłajczak A, et al. Smoking, alcohol, diet, dentition and sexual practices in the epidemiology of oral cancer in Poland. Eur J Cancer Prev. 2003;12(1):25-33.

9 Wang $\mathrm{X}, \mathrm{Xu}$ J, Wang L, Liu C, Wang H. The role of cigarette smoking and alcohol consumption in the differentiation of oral squamous cell carcinoma for the males in China. J Cancer Res Ther. 2015;11(1):141-5.

10 Hsiao JR, Chang CC, Lee WT, Huang CC, Ou CY, Tsai ST, et al. The interplay between oral microbiome, lifestyle factors and genetic polymorphisms in the risk of oral squamous cell carcinoma. Carcinogenesis. 2018;39(6): 778-87.

11 Bernardes VF, Diniz MG, Silva JC, Moraes DC, De Marco L, Gomes CC, et al. Lack of association between denture trauma and loss of heterozygosity confronts the proposed pathologic role of chronic mucosal trauma in oral carcinogenesis. J Oral Pathol Med. 2019; 48(5):421-3.

12 Dionne KR, Warnakulasuriya S, Zain RB, Cheong SC. Potentially malignant disorders of the oral cavity: current practice and future directions in the clinic and laboratory. Int $\mathrm{J}$ Cancer. 2015;136(3):503-15.

13 Porta C, Larghi P, Rimoldi M, Totaro MG, Allavena P, Mantovani A, et al. Cellular and molecular pathways linking inflammation and cancer. Immunobiology. 2009;214(9-10): 761-77.

14 Dvorak HF. Tumors: wounds that do not heal. Similarities between tumor stroma generation and wound healing. N Engl J Med. 1986;315(26):1650-9.

15 Mantovani A, Allavena P, Sica A, Balkwill F. Cancer-related inflammation. Nature. 2008; 454(7203):436-44.

16 Cirri P, Chiarugi P. Cancer-associated-fibroblasts and tumour cells: a diabolic liaison driving cancer progression. Cancer Metastasis Rev. 2012;31(1-2):195-208.

17 Said N, Frierson HF, Sanchez-Carbayo M, Brekken RA, Theodorescu D. Loss of SPARC in bladder cancer enhances carcinogenesis and progression. J Clin Invest. 2013;123(2): 751-66.

18 Dvorak HF. Tumors: wounds that do not heal-a historical perspective with a focus on the fundamental roles of increased vascular permeability and clotting. Semin Thromb Hemost. 2019;45(6):576-92.

19 Hua Y, Bergers G. Tumors vs. chronic wounds: an immune cell's perspective. FrontImmunol. 2019;10:2178.

20 Tao Y, Shen H, Liu Y, Li G, Huang Z, Liu Y. IL-23R in laryngeal cancer: a cancer immu- noediting process that facilitates tumor cell proliferation and results in cisplatin resistance. Carcinogenesis. 2021 Feb 11;42(1): $118-26$.

21 Mittal D, Gubin MM, Schreiber RD, Smyth MJ. New insights into cancer immunoediting and its three component phases: elimination, equilibrium and escape. Curr Opin immunol. 2014;27:16-25

22 O'Donnell JS, Teng MWL, Smyth MJ. Cancer immunoediting and resistance to $\mathrm{T}$ cell-based immunotherapy. Nature Rev Clin Oncol. 2019;16:151-67.

23 Bingle L, Brown NJ, Lewis CE. The role of tumour-associated macrophages in tumour progression: implications for new anticancer therapies. J Pathol. 2002;196(3):254-65.

24 Lewis CE, Pollard JW. Distinct role of macrophages in different tumor microenvironments. Cancer Res. 2006;66(2):605-12.

25 Komohara Y, Ohnishi K, Kuratsu J, Takeya $\mathrm{M}$. Possible involvement of the M2 anti-inflammatory macrophage phenotype in growth of human gliomas. J Pathol. 2008; 216(1):15-24.

26 Wynn TA. Type 2 cytokines: mechanisms and therapeutic strategies. Nat Rev Immunol. 2015; 15(5):271-82.

27 Gordon S. Alternative activation of macrophages. Nat Rev Immunol. 2003;3(1):23-35.

28 Mosser DM. The many faces of macrophage activation. J Leukoc Biol. 2003;73(2):209-12.

29 Takeya M, Komohara Y. Role of tumor-associated macrophages in human malignancies: friend or foe? Pathol Int. 2016;66(9):491505 .

30 Balkwill FR, Mantovani A. Cancer-related inflammation: common themes and therapeutic opportunities. Semin Cancer Biol. 2012; 22(1):33-40.

31 Sica A, Larghi P, Mancino A, Rubino L, Porta C, Totaro MG, et al. Macrophage polarization in tumour progression. Semin Cancer Biol. 2008;18(5):349-55.

32 Mosser DM, Edwards JP. Exploring the full spectrum of macrophage activation. Nat Rev Immunol. 2008;8(12):958-69. 
33 Murray PJ, Wynn TA. Obstacles and opportunities for understanding macrophage polarization. J Leukoc Biol. 2011;89(4):557-63.

34 Kwon Y, Kim M, Kim Y, Jung HS, Jeoung D. Exosomal microRNAs as mediators of cellular interactions between cancer cells and macrophages. Front Immunol. 2020 Jun; 11:1167.

35 Pan Y, Yu Y, Wang X, Zhang T. Tumor-associated macrophages in tumor immunity. Front Immunol. 2020 Dec;11:583084.

36 Mantovani A, Sozzani S, Locati M, Allavena P, Sica A. Macrophage polarization: tumorassociated macrophages as a paradigm for polarized M2 mononuclear phagocytes. Trends Immunol. 2002 Nov;23(11):549-55.

$37 \mathrm{Lu} \mathrm{J}, \mathrm{Ma} \mathrm{L}$. The role of tumor-associated macrophages in the development, metastasis and treatment of breast cancer. Pathol Res Pract. 2020 Sep;216(9):153085.

$38 \mathrm{Tu}$ D, Dou J, Wang M, Zhuang H, Zhang X. M2 macrophages contribute to cell proliferation and migration of breast cancer. Cell Biol Int. 2021 Apr;45(4):831-8.

39 Lv J, Feng ZP, Chen FK, Liu C, Jia L, Liu PJ, et al. M2-like tumor-associated macrophagessecreted Wnt 1 and Wnt3a promotes dedifferentiation and metastasis via activating $\beta$-catenin pathway in thyroid cancer. Mol Carcinog. 2021 Jan;60(1):25-37.

40 Wang Y-Y, Chen H-D, Lo S, Chen Y-K, Huang Y-C, Hu SC-S, et al. Visfatin enhances breast cancer progression through CXCL1 induction in tumor-associated macrophages. Cancers. 2020 Nov;12(12):3526

41 Yokozaki H, Koma YI, Shigeoka M, Nishio M. Cancer as a tissue: the significance of cancerstromal interactions in the development, morphogenesis and progression of human upper digestive tract cancer. Pathol Int. 2018 Jun;68(6):334-52.

42 Kodama T, Koma YI, Arai N, Kido A, Urakawa N, Nishio M, et al. CCL3-CCR5 axis contributes to progression of esophageal squamous cell carcinoma by promoting cell migration and invasion via Akt and ERK pathways. Lab Invest. 2020 Sep;100(9):114057.

43 Jiang Y, Han Q, Zhao H, Zhang J. Promotion of epithelial-mesenchymal transformation by hepatocellular carcinoma-educated macrophages through $\mathrm{Wnt} 2 \mathrm{~b} / \beta$-catenin/c-Myc signaling and reprogramming glycolysis. J Exp Clin Cancer Res. 2021 Jan;40(1):13.

44 Yuan H, Lin Z, Liu Y, Jiang Y, Liu K, Tu M, et al. Intrahepatic cholangiocarcinoma induced M2-polarized tumor-associated macrophages facilitate tumor growth and invasiveness. Cancer Cell Int. 2020 Dec;20(1):586.

45 Liu M, Zhong YB, Shao J, Zhang C, Shi C. Tumor-associated macrophages promote human hepatoma Huh-7 cell migration and invasion through the Gli2/IGF-II/ERK1/2 axis by secreting TGF- $\beta 1$. Cancer Biol Ther. 2020 Nov;21(11):1041-50.

46 Fujiwara Y, Komohara Y, Ikeda T, Takeya M. Corosolic acid inhibits glioblastoma cell proliferation by suppressing the activation of sig- nal transducer and activator of transcription-3 and nuclear factor-kappa B in tumor cells and tumor-associated macrophages. Cancer Sci. 2011 Jan;102(1):206-11.

47 Fujiwara Y, Komohara Y, Kudo R, Tsurushima K, Ohnishi K, Ikeda T, et al. Oleanolic acid inhibits macrophage differentiation into the M2 phenotype and glioblastoma cell proliferation by suppressing the activation of STAT3. Oncol Rep. 2011 Dec;26(6):1533-7.

48 Rolny C, Mazzone M, Tugues S, Laoui D, Johansson I, Coulon C, et al. HRG inhibits tumor growth and metastasis by inducing macrophage polarization and vessel normalization through downregulation of PlGF. Cancer Cell. 2011 Jan;19(1):31-44.

49 Huang Y, Yuan J, Righi E, Kamoun WS, Ancukiewicz M, Nezivar J, et al. Vascular normalizing doses of antiangiogenic treatment reprogram the immunosuppressive tumor microenvironment and enhance immunotherapy. Proc Natl Acad Sci U S A. 2012 Oct; 109(43):17561-6.

50 Chen P, Bonaldo P. Role of macrophage polarization in tumor angiogenesis and vessel normalization: implications for new anticancer therapies. Int Rev Cell Mol Biol. 2013;301: $1-35$.

51 Guo C, Buranych A, Sarkar D, Fisher PB, Wang XY. The role of tumor-associated macrophages in tumor vascularization. Vasc Cell. 2013 Dec;5(1):20

52 Jarosz-Biej M, Kamińska N, Matuszczak S, Cichoń T, Pamuła-Piłat J, Czapla J, et al. M1like macrophages change tumor blood vessels and microenvironment in murine melanoma. PLoS One. 2018 Jan;13(1):e0191012.

53 Pollard JW. Tumour-educated macrophages promote tumour progression and metastasis. Nat Rev Cancer. 2004;4(1):71-8.

54 Mantovani A, Sozzani S, Locati M, Allavena P, Sica A. Macrophage polarization: tumorassociated macrophages as a paradigm for polarized M2 mononuclear phagocytes. Trends Immunol. 2002;23(11):549-55.

55 Okubo M, Kioi M, Nakashima H, Sugiura K, Mitsudo K, Aoki I, et al. M2-polarized macrophages contribute to neovasculogenesis, leading to relapse of oral cancer following radiation. Sci Rep. 2016;6:27548.

56 Fujii N, Shomori K, Shiomi T, Nakabayashi M, Takeda C, Ryoke K, et al. Cancer-associated fibroblasts and CD163-positive macrophages in oral squamous cell carcinoma: their clinicopathological and prognostic significance. J Oral Pathol Med. 2012;41(6):444-51.

57 He KF, Zhang L, Huang CF, Ma SR, Wang YF, Wang WM, et al. CD163+ tumor-associated macrophages correlated with poor prognosis and cancer stem cells in oral squamous cell carcinoma. Biomed Res Int. 2014;2014: 838632.

58 Weber M, Iliopoulos C, Moebius P, BüttnerHerold M, Amann K, Ries J, et al. Prognostic significance of macrophage polarization in early stage oral squamous cell carcinomas. Oral Oncol. 2016;52:75-84.
$59 \mathrm{Hu}$ Y, He MY, Zhu LF, Yang CC, Zhou ML, Wang $\mathrm{Q}$, et al. Tumor-associated macrophages correlate with the clinicopathological features and poor outcomes via inducing epithelial to mesenchymal transition in oral squamous cell carcinoma. J Exp Clin Cancer Res. 2016;35:12.

60 Alves AM, Diel LF, Lamers ML. Macrophages and prognosis of oral squamous cell carcinoma: a systematic review. J Oral Pathol Med. 2018;47(5):460-7.

61 Xiao M, Zhang J, Chen W, Chen W. M1-like tumor-associated macrophages activated by exosome-transferred THBS1 promote malignant migration in oral squamous cell carcinoma. J Exp Clin Cancer Res. 2018;37(1): 143.

62 Mori K, Haraguchi S, Hiori M, Shimada J, Ohmori Y. Tumor-associated macrophages in oral premalignant lesions coexpress CD163 and STAT1 in a Th1-dominated microenvironment. BMC Cancer. 2015;15:573.

63 Lahav Y, Shats M, Huszar M, Haimovich Y, Warman M, Halperin D, et al. Local inflammatory reaction to benign, pre-malignant and malignant glottic lesions: a matched casecontrol study. Clin Otolaryngol. 2019;44(4): 628-38.

$64 \mathrm{Su}$ C, Jia S, Liu H. Immunolocalization of CD163+ tumor-associated macrophages and symmetric proliferation of Ki-67 as biomarkers to differentiate new different grades of laryngeal dysplasia. Am J Clin Pathol. 2017; 149(1):8-16.

65 Taniyama D, Taniyama K, Kuraoka K, Zaitsu J, Saito A, Nakatsuka H, et al. Long-term follow-up study of gastric adenoma; tumor-associated macrophages are associated to carcinoma development in gastric adenoma. Gastric Cancer. 2017;20(6):929-39.

66 Taniyama D, Taniyama K, Kuraoka K, Yamamoto H, Zaitsu J, Saito A, et al. CD204positive tumor-associated macrophages relate to malignant transformation of colorectal adenoma. Anticancer Res. 2019;39(6): 2767-75.

67 Maglietta A, Maglietta R, Staiano T, Bertoni $\mathrm{R}$, Ancona N, Marra G, et al. The immune landscapes of polypoid and nonpolypoid precancerous colorectal lesions. PLoS One. 2016; 11(7):e0159373.

68 Ma HY, Yamamoto G, Xu J, Liu X, Karin D, Kim JY, et al. IL-17 signaling in steatotic hepatocytes and macrophages promotes hepatocellular carcinoma in alcohol-related liver disease. J Hepatol. 2020;72(5):946-59.

69 Sato Y, Kinoshita M, Takemura S, Tanaka S, Hamano G, Nakamori S, et al. The PD-1/PDL1 axis may be aberrantly activated in occupational cholangiocarcinoma. Pathol Int. 2017;67(3):163-70

70 Hammes LS, Tekmal RR, Naud P, Edelweiss MI, Kirma N, Valente PT, et al. Macrophages, inflammation and risk of cervical intraepithelial neoplasia (CIN) progression: clinicopathological correlation. Gynecol Oncol. 2007; 105(1):157-65. 
71 Chen XJ, Han LF, Wu XG, Wei WF, Wu LF, Yi HY, et al. Clinical significance of CD163+ and CD68+ tumor-associated macrophages in high-risk HPV-related cervical cancer. J Cancer. 2017;8(18):3868-75.

72 Swangphon P, Pientong C, Sunthamala N, Bumrungthai S, Azuma M, Kleebkaow P, et al. Correlation of circulating CD64(+)/ CD163(+) monocyte ratio and stroma/peritumoral CD163(+) monocyte density with human papillomavirus infected cervical lesion severity. Cancer Microenviron. 2017;10: $77-85$.

73 Jiang XF, Tang QL, Li HG, Shen XM, Luo X, Wang XY, et al. Tumor-associated macrophages correlate with progesterone receptor loss in endometrial endometrioid adenocarcinoma. J Obstet Gynaecol Res. 2013;39(4): 855-63.

74 Kawamura K, Komohara Y, Takaishi K, Katabuchi $\mathrm{H}$, Takeya M. Detection of M2 macrophages and colony-stimulating factor $1 \mathrm{ex}$ pression in serous and mucinous ovarian epithelial tumors. Pathol Int. 2009;59(5):300-5.

75 Fujii T, Shimada K, Asai O, Tanaka N, Fujimoto K, Hirao K, et al. Immunohistochemical analysis of inflammatory cells in benign and precancerous lesions and carcinoma of the prostate. Pathobiology. 2013;80(3):119-26.

76 Campbell MJ, Baehner F, O’Meara T, Ojukwu E, Han B, Mukhtar R, et al. Characterizing the immune microenvironment in high-risk ductal carcinoma in situ of the breast. Breast Cancer Res Treat. 2017;161(1):17-28.

77 Chen XY, Thike AA, Md Nasir ND, Koh VCY, Bay BH, Tan PH. Higher density of stromal M2 macrophages in breast ductal carcinoma in situ predicts recurrence. Virchows Archiv. 2020 Jun;476(6):825-33.

78 Shigeoka M, Koma YI, Nishio M, Komori T, Yokozaki H. CD163(+) macrophages infiltration correlates with the immunosuppressive cytokine interleukin 10 expression in tongue leukoplakia. Clin Exp Dent Res. 2019;5:62737.

79 Essa AA, Yamazaki M, Maruyama S, Abé T, Babkair H, Raghib AM, et al. Tumour-associated macrophages are recruited and differentiated in the neoplastic stroma of oral squamous cell carcinoma. Pathology. 2016;48(3): 219-27.

80 Kouketsu A, Sato I, Oikawa M, Shimizu Y, Saito H, Tashiro K, et al. Regulatory T cells and M2-polarized tumour-associated macrophages are associated with the oncogenesis and progression of oral squamous cell carcinoma. Int J Oral Maxillofac Surg. 2019; 48(10):1279-88.
81 Weber M, Wehrhan F, Baran C, Agaimy A, Büttner-Herold M, Öztürk H, et al. Malignant transformation of oral leukoplakia is associated with macrophage polarization. J Transl Med. 2020;18(1):11.

82 Ye X, Zhang J, Lu R, Zhou G. Signal regulatory protein $\alpha$ associated with the progression of oral leukoplakia and oral squamous cell carcinoma regulates phenotype switch of macrophages. Oncotarget. 2016; 7(49): 81305-21.

83 Stasikowska-Kanicka O, WągrowskaDanilewicz M, Danilewicz M. T cells are involved in the induction of macrophage phenotypes in oral leukoplakia and squamous cell carcinoma-a preliminary report. J Oral Pathol Med. 2018;47(2):136-43.

84 Shigeoka M, Koma YI, Kodama T, Nishio M, Akashi M, Yokozaki H. Intraepithelial CD163(+) macrophages in tongue leukoplakia biopsy: a promising tool for cancer screening. Oral Dis. 2020 Apr;26(3):527-36.

85 Shigeoka M, Koma YI, Kodama T, Nishio M, Akashi M, Yokozaki H. CD163(+) foamy macrophages are associated with the morphogenesis of oral verruciform xanthoma through angiogenesis by VEGF expression: an immunohistochemical study. Dent J. 2020 Feb 14;8(1):18.

86 Schenk P. [The ultrastructure of dyskeratotic and dysplastic keratinocytes in oral epithelium (author's transl)]. HNO. 1976;24(5):14760.

87 Loning T, Burkhardt A. Dyskeratosis in human and experimental oral precancer and cancer. An immunohistochemical and ultrastructural study in men, mice and rats. Arch Oral Biol. 1982;27:361-6.

88 Bondad-Palmario GG. Histological and immunochemical studies of oral leukoplakia: phenotype and distribution of immunocompetent cells. J Philipp Dent Assoc. 1995;47(1): 3-18.

89 Syafriadi M, Cheng J, Jen KY, Ida-Yonemochi H, Suzuki M, Saku T. Two-phase appearance of oral epithelial dysplasia resulting from focal proliferation of parabasal cells and apoptosis of prickle cells. J Oral Pathol Med. 2005; 34(3):140-9.

90 Sun Y, Liu N, Guan X, Wu H, Sun Z, Zeng H. Immunosuppression induced by chronic inflammation and the progression to oral squamous cell carcinoma. Mediators Inflamm. 2016;2016:5715719.

91 Yagyuu T, Hatakeyama K, Imada M, Kurihara M, Matsusue Y, Yamamoto K, et al. Programmed death ligand 1 (PD-L1) expression and tumor microenvironment: implications for patients with oral precancerous lesions. Oral Oncol. 2017;68:36-43.
92 Lucio PS, Ribeiro DC, Aguiar MC, Alves PM, Nonaka CF, Godoy GP. Tumor-associated macrophages (TAMs): clinical-pathological parameters in squamous cell carcinomas of the lower lip. Braz Oral Res. 2016; 30:e95.

93 Kawsar HI, Weinberg A, Hirsch SA, Venizelos A, Howell S, Jiang B, et al. Overexpression of human beta-defensin-3 in oral dysplasia: potential role in macrophage trafficking. Oral Oncol. 2009;45(8):696-702.

94 Shigeoka M, Koma YI, Kanzawa M, Akashi M, Yokozaki H. Intraepithelial macrophage expressing CD163 is a histopathological clue to evaluate the malignant potency of oral lichenoid condition: a case report and immunohistochemical investigation. Diagnostics. 2020 Aug 23;10(9):624.

95 Usami Y, Ishida K, Sato S, Kishino M, Kiryu $\mathrm{M}$, Ogawa $\mathrm{Y}$, et al. Intercellular adhesion molecule-1 (ICAM-1) expression correlates with oral cancer progression and induces macrophage/cancer cell adhesion. Int J Cancer. 2013;133(3):568-78.

96 Weber M, Moebius P, Büttner-Herold M, Amann K, Preidl R, Neukam FW, et al. Macrophage polarisation changes within the time between diagnostic biopsy and tumour resection in oral squamous cell carcinomas: an immunohistochemical study. Br J Cancer. 2015;113(3):510-9.

97 Funayama A, Maruyama S, Yamazaki M, Al-Eryani K, Shingaki S, Saito C, et al. Intraepithelially entrapped blood vessels in oral carcinoma in-situ. Virchows Arch. 2012;460(5):473-80.

98 Poulopoulos AK, Andreadis D, Markopoulos AK. Expression of matrix metalloproteinases 9 and 12 in actinic cheilitis. World J Exp Med. 2013;3(3):43-9.

99 Xiao L, Zhang Q, Peng Y, Wang D, Liu Y. The effect of periodontal bacteria infection on incidence and prognosis of cancer: a systematic review and meta-analysis. Medicine. 2020;99(15):e19698.

100 Yu T, Zhao L, Huang X, Ma C, Wang Y, Zhang J, et al. Enhanced activity of the macrophage M1/M2 phenotypes and phenotypic switch to M1 in periodontal infection. J Periodontol. 2016;87(9):1092-102.

101 Kang S, Zhang C, Ohno T, Azuma M. Unique B7-H1 expression on masticatory mucosae in the oral cavity and trans-coinhibition by $\mathrm{B} 7-\mathrm{H} 1$-expressing keratinocytes regulating $\mathrm{CD} 4(+) \mathrm{T}$ cell-mediated mucosal tissue inflammation. Mucosal Immunol. 2017;10:650-60.
Novel View on Oral Carcinogenesis Focusing on Macrophages
Pathobiology 2021;88:327-337 DOI: $10.1159 / 000515922$ 